NBER WORKING PAPER SERIES

\title{
RISK MANAGEMENT AND CLIMATE CHANGE
}

\author{
Howard Kunreuther \\ Geoffrey Heal \\ Myles Allen \\ Ottmar Edenhofer \\ Christopher B. Field \\ Gary Yohe \\ Working Paper 18607 \\ http://www.nber.org/papers/w18607 \\ NATIONAL BUREAU OF ECONOMIC RESEARCH \\ 1050 Massachusetts Avenue \\ Cambridge, MA 02138 \\ December 2012
}

Thanks to Linus Mattauch for research assistance and to Malte Meinshausen for the data used in Figure 1. Simon Dietz, Kristie Ebi, Christian Gollier, Robin Gregory, Benjamin Horton, Elmar Kriegler, Katharine Mach, Michael Mastrandrea, Anthony Millner, Michael Oppenheimer and Christian Träger provided comments on earlier versions of the paper. Partial support for this research came from the Wharton Risk Management and Decision Processes Center's. Extreme Events project, the National Science Foundation (SES-1062039 and 1048716), the Travelers Foundation, the Center for Climate and Energy Decision Making (NSF Cooperative Agreement SES-0949710 with Carnegie Mellon University), the Center for Research on Environmental Decisions (CRED; NSF Cooperative Agreement SES-0345840 to Columbia University) and CREATE at University of Southern California. The views expressed herein are those of the authors and do not necessarily reflect the views of the National Bureau of Economic Research.

NBER working papers are circulated for discussion and comment purposes. They have not been peerreviewed or been subject to the review by the NBER Board of Directors that accompanies official NBER publications.

(C) 2012 by Howard Kunreuther, Geoffrey Heal, Myles Allen, Ottmar Edenhofer, Christopher B. Field, and Gary Yohe. All rights reserved. Short sections of text, not to exceed two paragraphs, may be quoted without explicit permission provided that full credit, including $(\mathrm{C}$ notice, is given to the source. 
Risk Management and Climate Change

Howard Kunreuther, Geoffrey Heal, Myles Allen, Ottmar Edenhofer, Christopher B. Field, and Gary Yohe

NBER Working Paper No. 18607

December 2012

JEL No. C02,Q54

\begin{abstract}
The selection of climate policies should be an exercise in risk management reflecting the many relevant sources of uncertainty. Studies of climate change and its impacts rarely yield consensus on the distribution of exposure, vulnerability, or possible outcomes. Hence policy analysis cannot effectively evaluate alternatives using standard approaches such as expected utility theory and benefit-cost analysis. This Perspective highlights the value of robust decision-making tools designed for situations, such as evaluating climate policies, where generally agreed-upon probability distributions are not available and stakeholders differ in their degree of risk tolerance. This broader risk management approach enables one to examine a range of possible outcomes and the uncertainty surrounding their likelihoods.
\end{abstract}

Howard Kunreuther

Operations and Information Management

The Wharton School

University of Pennsylvania

3730 Walnut Street, $500 \mathrm{JMHH}$

Philadelphia, PA 19104-6366

and NBER

kunreuther@wharton.upenn.edu

Geoffrey Heal

Graduate School of Business

616 Uris Hall

Columbia University

New York, NY 10027-6902

and NBER

gmh1@columbia.edu

Myles Allen

School of Geography and the Environment

South Parks Road

OX1 3QY

myles.allen@ouce.ox.ac.uk
Ottmar Edenhofer

Potsdam Institute for Climate

P.O. 601203

D-14412 Potsdam

Ottmar.Edenhofer@pik-potsdam.de

Christopher B. Field

Carnegie Institution for Science

Department of Global Ecology

260 Panama Street

Stanford, CA 94305

cfield@ciw.edu

Gary Yohe

Department of Economics

Wesleyan University

PAC 328

Middleton, CT 06459

gyohe@wesleyan.edu 


\section{Introduction}

The scientific understanding of climate change and its impacts has increased dramatically in recent years, but several interacting sources of uncertainty mean that future climate change and its impacts will not be known with precision for the foreseeable future. Some uncertainties involve the path of global socioeconomic development, the way it affects the commitment by countries to use energy efficient technologies and how greenhouse gas emissions might respond to specific climate-related policies. Other uncertainties involve internal variability and incomplete understanding of the climate system and broader Earth-system feedbacks. Still other uncertainties involve the way that changes in climate translate to impacts such as changes in water availability, agricultural production, sea level rise, or heat waves in different parts of the world. A final set involves the evolution of assets at risk (exposure) both in physical and in monetary terms and the level of protection that can be undertaken to reduce their vulnerability to potential losses (i.e., adaptation measures). The implication of these interacting sources of uncertainty is that choosing among climate policies is intrinsically an exercise in risk management.

A principal purpose of risk management is to evaluate strategies for responding to an uncertain threat. To illustrate this point in the context of a simple example, consider a coastal community in Florida deciding whether land 3 meters above sea level is a suitable location for construction of a new residential development to be occupied for most of the current century. Suppose that the best estimate of the maximum storm surge plus sea level rise over this period is 2 meters. In this case, the project looks safe. But if there is a chance of a storm surge plus sea level rise that is substantially greater, it is less attractive. So a forecast of 2 meters is very different from a 
forecast of 1 to 4 meters with 2 meters as the most likely outcome. Key decision-makers in the community need to know the range of possible outcomes so they can determine the robustness of policy decisions. The final decision on whether to build the residential development, and the maximum it is sensible to pay for the land, will be influenced by the characterization of the risk.

For decisions regarding climate policy, the central importance of uncertainty has long been recognized. Schneider ${ }^{1}$ and colleagues were pioneers in posing policy questions in the context of risk and in introducing conceptual frameworks for managing that risk. Recent research takes a more formal approach, highlighting the importance of specifying uncertainty as a key policy input. Worst-case scenarios -- the possibility of extremely costly outcomes with small but positive probabilities -- can have massive impacts on the cost-benefit analysis of climate change mitigation, and on the perspectives of key decision-makers. These low-probability highconsequence events have motivated a focus on the tail of the distribution of outcomes ${ }^{2,3}$. For example, a $5 \%$ chance of a truly unacceptable temperature increase may have a significant impact when evaluating the expected benefits and costs of climate adaptation and mitigation policies.

To date, much of the focus in assessments of climate change and its impacts has been on central tendencies. Uncertainty in future climates is most often represented as the range of outcomes generated by different climate models run for a range of scenarios. There are, however, numerous physical grounds and some observational ones for suspecting that such ensembles of opportunity may not account for all sources of uncertainty. Some of the open issues relate to the 
ways the models are calibrated. Others reflect incomplete understanding of important feedbacks, like those involving the carbon cycle.

Relatively few studies systematically explore the uncertainty in climate model parameters or structure. Those studies that have fall into two categories. One set undertakes a large number of runs using simplified climate models: these typically produce rather broad ranges of uncertainty, but this may simply reflect the difficulty of using observations to constrain simple models. ${ }^{1}$ The other set uses more complex models but much smaller ensembles: these typically give narrower ranges that may simply reflect inadequate exploration of parameter and structural uncertainty. ${ }^{2}$ The few studies that use large ensembles and complex models ${ }^{5,6}$ have found relatively broad ranges.

Many impact studies use climate forcing from multiple climate models or multiple climate scenarios but few provide a probability distribution of possible impacts for a given climate forcing scenario. The result is a striking gap between the available information and the demand for information framed in the context of risk and uncertainty that form the essential lens through which the entire issue must be viewed. One possible response to this gap is a greater emphasis on characterizing well-defined probability density functions (PDFs) as a foundation for policy advice. There have been many attempts to do this, for example Kolstadt ${ }^{9}$, Fisher and Narain ${ }^{10}$, or for a survey, Heal and Kristrom. ${ }^{11}$ An alternative is a fundamental change in the focus of future research and the communication of uncertainty as it relates to climate change, with increased

\footnotetext{
${ }^{1}$ For more details on this point see Yohe, Andronova and Schlesinger ${ }^{4}$, Piani et al. ${ }^{5}$ and Rowlands et al. ${ }^{6}$

${ }^{2}$ See Shiogama et al. ${ }^{7}$ and Yokohata et al. ${ }^{8}$ for more details on these complex models with smaller ensembles.
} 
emphasis on probabilities based on subjective likelihoods of various outcomes. ${ }^{12}$ The problem with proposing these probabilities, however, is that they may be divorced from the data available and may thus appear to be arbitrary.

A third option, the focus of this paper, is to take advantage of available tools for decision support that do not depend on information about the entire PDFs for each scenario. Some of the approaches that evaluate alternatives, such as expected utility theory, cannot deal with situations with limited or no information on probabilities.

\section{Incorporating Uncertainty in Climate Risk Management}

The challenge in evaluating alternative strategies for addressing climate change issues is that many risk assessments and climate impact studies provide ranges of outcomes, but with relatively little information on probability distributions. For example, the IPCC AR4 presents most of its climate model projections based on multi-model ensembles. For line or bar charts, uncertainty is represented variously as the $5 \%$ to $95 \%$ range, means \pm 1 standard deviation, mean plus $60 \%$ to mean minus $40 \%$, and results of all models plotted individually. For maps of projected precipitation, multi-model means are shown only where at least $66 \%$ of the models agree on the sign of the change, with stippling indicating areas where $90 \%$ of the models agree on the sign of the change.

A recent report of the IPCC (SREX) $)^{14}$ presents extremes of temperature and precipitation in terms of future return intervals for the regionally most extreme value in 20 years, showing the median and the range across $50 \%$ and $100 \%$ of the models that participated in the multi-model 
intercomparison project. While this is a major advance in the presenting probabilistic outcomes, it is still far from providing complete PDFs.

In the absence of complete PDFs, one way to specify information about the tails of the distribution is to leave off extremes when the likelihood of an outcome is sufficiently small that key decision makers feel that they can ignore its consequences. For example, if climate scientists agree that it is highly unlikely that the global average temperature increase will exceed $6{ }^{\circ} \mathrm{C}$ by 2050 , then the consequences of this possible outcome would not be considered in choosing between alternatives. More generally, this process entails specifying a threshold probability and removing extremes that have lower probabilities in determining risk management strategies for dealing with climate change.

Insurers and reinsurers utilize this approach in determining the amount of coverage that they are willing to offer against a particular risk. They diversify their portfolio of policies to keep the annual probability of a major loss below some threshold level (e.g., 1 in 1,000). ${ }^{15}$ This behavior is in the spirit of a classic paper by Roy ${ }^{16}$ on safety-first behavior.

Consider our example of the coastal community in Florida reviewing a development at 3 meters above sea level. One way of evaluating this is to undertake a benefit-cost analysis delineating climate change scenarios where the construction costs, operating expenses and restoration costs should it be flooded exceed the expected benefits. If the cumulative probability of these scenarios is below the required safety level, the facility should be constructed at 3 meters. If these criteria are not met, then one could repeat the benefit-cost analysis for alternative 
adaptation measures such as elevating the facility so its foundation is at 4 meters above sea level. If there is no adaptation measure where the expected benefit/cost ratio exceeds 1 also meets the safety first criteria, then the community may not want to build the facility.

\section{Risk Management and Ambiguity}

In contrast to risk situations where the probabilities are known, ambiguous (or imprecise) situations are ones in which the uncertainty about possible outcomes cannot be objectively characterized by a single well-defined PDF. Individuals and institutions are ambiguity-averse and will pay a premium to reduce the ambiguity that they face. ${ }^{17,18,19}$ For example, estimates of the PDF of equilibrium climate sensitivity (ECS, or multi-century time-scale warming in response to a doubling of atmospheric $\mathrm{CO}_{2}$ ) differ greatly among approaches and data sets. To illustrate this point, representative PDFs of ECS are depicted in Figure 1. Estimates of the probability of ECS exceeding $4.5^{\circ} \mathrm{C}$ range from less than $2 \%$ to over $50 \%$ in different studies. ${ }^{20}$ Milner, Dietz and Heal use this example to show that the impact of such imprecision on decision processes can be substantial. ${ }^{13}$ 


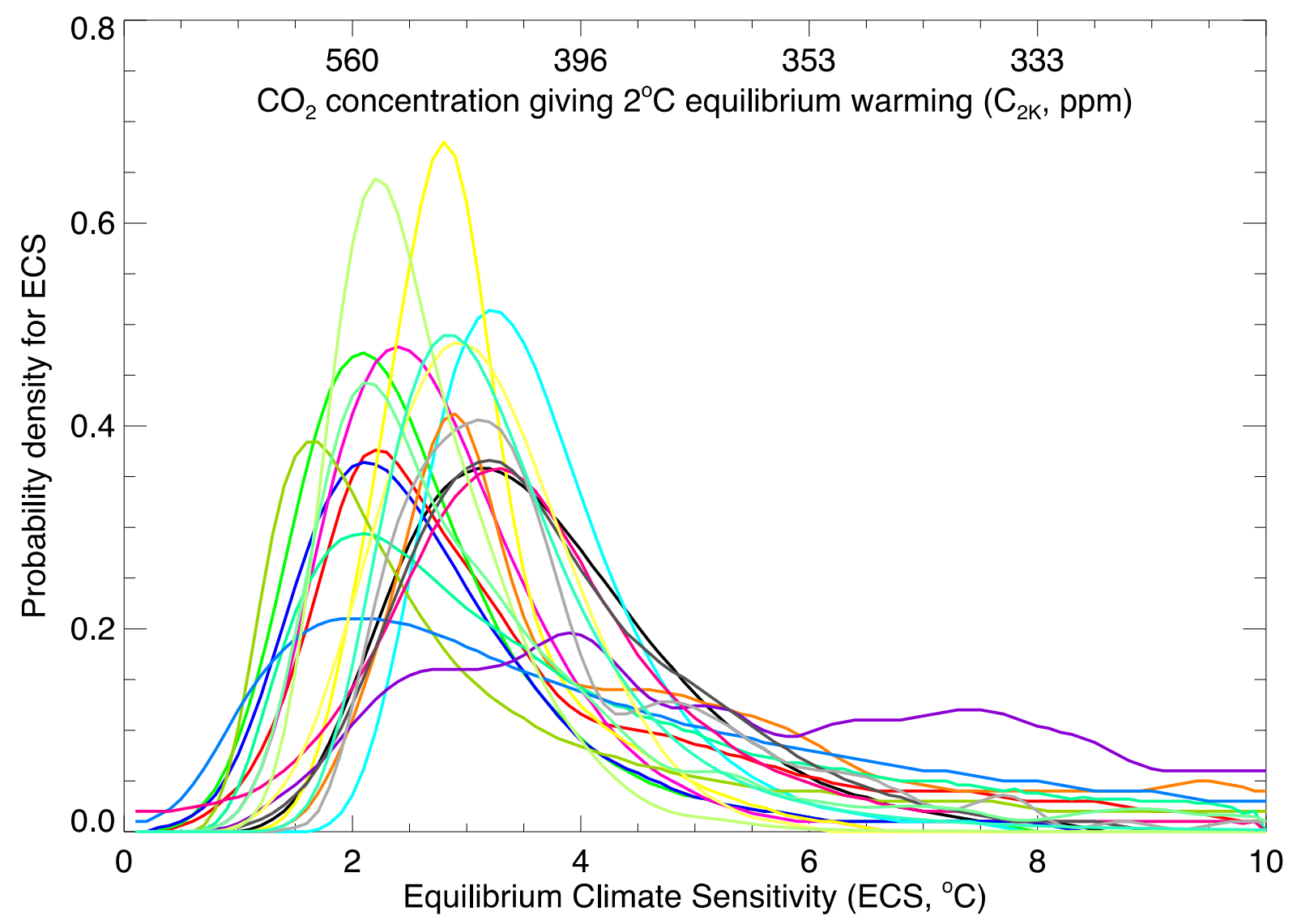

Figure 1: Estimated probability distributions for (bottom axis) Equilibrium Climate Sensitivity from various published studies, collated by ref. 16, and (top axis) corresponding concentrations of $\mathrm{CO}_{2}$ consistent with a long-term $\mathrm{CO}_{2}$-induced warming $T_{\max }$ of $2^{\circ} \mathrm{C}$, given by the expression $C_{2 \mathrm{~K}}=C_{\text {pre-industrial }} \exp \left(\ln (2) T_{\max } / \mathrm{ECS}\right)$. Current concentrations are $397 \mathrm{ppm}$.

Pursuing this example, the top axis of Figure 1 shows concentrations of $\mathrm{CO}_{2}$ consistent with $2^{\circ} \mathrm{C}$ of warming ${ }^{21}$ corresponding to the values of ECS on the bottom axis. Suppose emissions decay exponentially at an average rate $r$, and $f$ is the average future airborne fraction (circa $45 \%$ over recent decades). $\mathrm{CO}_{2}$ concentrations would then increase by a further $f / r$ times current emissions $E_{0}$ of about $10 \mathrm{GtC}$ per year (equivalent to $4.7 \mathrm{ppm}$ atmospheric $\mathrm{CO}_{2}$ ). Limiting $\mathrm{CO}_{2}$ - 
induced warming to $2^{\circ} \mathrm{C}$ would therefore require emissions to fall at an average rate of $1.3 \% /$ year (so concentrations rise by a further $E_{0} f / r \approx 160 \mathrm{ppm}$ ) if ECS is $2^{\circ} \mathrm{C}$ and $4.4 \% /$ year if ECS is $3^{\circ} \mathrm{C}$, a major difference. Uncertainty matters in this range of ECS values. As shown in Figure 1, there is, however, a high level of consensus across studies that the probability of ECS $>3^{\circ} \mathrm{C}$ is $50 \%$ or more.

Meeting the $2^{\circ} \mathrm{C}$ goal for any value of ECS much greater than $3^{\circ} \mathrm{C}$, would require either offsetting the impact of $\mathrm{CO}_{2}$ with other forcings and/or deploying large-scale negative $\mathrm{CO}_{2}$ emission measures in the future. The scale of these measures will depend not only on the trajectory of emissions but also on changes in the airborne fraction and climate system response ${ }^{22}$ which will only become clear when emissions start to fall. Hence the steps required today to meet the $2^{\circ} \mathrm{C}$ goal are not qualitatively affected by ambiguity in the shape of the distribution for ECS above $3^{\circ} \mathrm{C}$.

Modeling decision-making under ambiguity requires a framework for rational choice in the absence of well-defined probabilities. Several have been proposed in the last two decades (see Gilboa $^{23}$ for a review). Millner, Dietz and Heal ${ }^{13}$ work with the framework developed by Klibanoff et al. ${ }^{24}$ that separates preferences and subjective beliefs, a hallmark of expected utility theory. Their model allows one to consider the distributions forecast by several approaches, for example, the ECS distributions in Figure 1. The authors demonstrate that aversion to ambiguity, given the different predictions, leads to a greater willingness to invest in climate change mitigation. 


\section{Non-Probabilistic Models for Making Choices}

Non-probabilistic approaches to decision-making, including minimax $\operatorname{regret}^{25}$ and maximin ${ }^{26}$ criteria, described in more detail below, can be applied when the probabilities of possible outcomes are not known.

The minimax regret approach requires the analyst to identify the regret associated with any policy. The regret is the difference between the value of the best policy in each state of the world and the value under the policy actually chosen. The optimal policy choice is that which minimizes, over all policy choices, the maximum regret (over all states) associated with a policy choice. Formally, if $\mathrm{S}$ is a state, and $\mathrm{P}$ a policy choice, $\mathrm{P}^{*}(\mathrm{~S})$ is the best policy choice conditional on $\mathrm{S}$ being the state, and $\mathrm{V}(\mathrm{S}, \mathrm{P})$ is the value of choosing policy $\mathrm{P}$ if the outcome is $\mathrm{S}$, then the goal is:

$\operatorname{Min}_{P} \operatorname{Max}_{S}\left\{V\left(S, P^{*}(S)\right)-V(S, P)\right\}$

Consider the application of this idea to the example of the Florida community determining whether or not to permit construction of a residential facility on the coast. To determine the optimal choice when using the minimax regret model, one first selects possible amounts of storm surge plus sea level rise and calculates the optimal design of the residential facility for each of these scenarios. Suppose there are $n$ climate scenarios, and the optimal facility design for scenario $j$ is labeled $j^{*}, j=1 \ldots n$. For every other possible design of the facility, calculate how far its outcome diverges in present value from the optimal choice for each climate scenario: this is the regret for that scenario. The maximum regret is the largest possible divergence between the outcome from the optimal choice $j *$ for scenario $j$ and the actual outcome over all possible 
scenarios if $j^{*}$ is chosen. The chosen option is the one that gives the lowest value of the maximum regret.

The maximin criterion $\left(\mathrm{Wald}^{26}\right)$ is far simpler: it involves ranking policies by their worst-case outcomes; the optimal policy is the one that has the best worst-case outcome. There is no concept of regret here and so no need to measure the differences between outcomes, but merely to rank them. It is more demanding to use the minimax regret criterion in that it requires us to compare differences between outcomes; however, one gains information in the process. Crucially, neither approach requires relative probabilities to be assigned to the different climate scenarios, although some threshold would be required to avoid results being dominated by entirely implausible outcomes.

\section{Robust Decision-Making}

Robust decision making (RDM) is a particular set of methods and tools developed over the last decade to support decision-making and policy analysis under conditions of ambiguity. RDM uses ranges or, more formally, sets of plausible probability distributions to describe deep uncertainty that play a role in evaluating alternative strategies for today and the future. In contrast to expected utility theory, it assesses different strategies on the basis of their robustness rather than their optimality. In the context of the design of a facility to reduce the likelihood of damage from storm surge and sea level rise, choosing Design 1* may be optimal based on a specific set of estimates of the likelihood of each scenario $j=1 \ldots . n$ occurring. However, Design $2^{*}$ may have a higher expected loss than Design 1* but much less variance in its outcomes, and thus be a preferred choice by the community. 
Lempert et al. ${ }^{27}$ review the application of a range of robust approaches to decisions with respect to mitigating or adapting to climate change. A World Resources Institute webpage on Managing Uncertainty (http://www.worldresourcesreport.org/decision-making-in-depth/managinguncertainty) summarizes several applications of robust decision/non-probabilistic approaches, each using various types of climate information. These applications include the Thames River Barrier, energy production in the Niger Basin, water management in Yemen, and flood risk management in a large southeast Asian metropolis. The examples illustrate how climate information can be used to identify various thresholds or bounding cases beyond which certain policies will fail. In some cases robust decision methods generate probability thresholds for certain scenarios above which a decision maker might choose a different risk management strategy. This threshold can then be compared to one or more probabilistic estimates from the literature, such as the study by Hall et al. ${ }^{28}$

\section{Conclusions}

Studies by the climate science and climate-change impacts communities have provided a range of possible outcomes of climate change. Formal approaches such as the maximization of expected utility or benefit-cost analysis are difficult to apply in the presence of ambiguity with respect to the distribution of future climate scenarios. For most issues relevant to policy choices, the solution is to utilize more robust approaches to risk management that do not require unambiguous probabilities. Risk management strategies designed to deal with the uncertainties that surround projections of climate change and their impacts can thus play an important role in supporting the development of sound policy options. 


\section{References}

1 Schneider, S.H. What is 'dangerous' climate change? Nature: 411: 17-19 (2001).

2 Weitzman, M. On modeling and interpreting the economics of catastrophic climate change. Review of Economics and Statistics 91(1): 1-19 (2009).

3 Dietz, S. High impact, low probability? An empirical analysis of risk in the economics of climate change. Climatic Change 103(3): 519-541 (2011).

4 Yohe, G., Andronova, N. \& Schlesinger, M. To Hedge or Not Against an Uncertain Climate, Science 306: 415-417. (2004).

5 Piani. C., Frame, D.J., Stainforth, D.A. \& Allen, M.R. Constraints on climate change from a multi-thousand member ensemble of simulations. Geophysical Research Letters 32: L23825 (2005).

6 Rowlands, D., Frame, D.J., Ackerley, D. et al Broad range of 2050 warming from an observationally constrained large climate model ensemble. Nature Geoscience, 5:256-260 doi:10.1038/ngeo1430 (2012).

$7 \underline{\text { Shiogama, H., Watanabe, M., Yoshimori, M., Yokohata, T., and Ogura, T., et al. Perturbed }}$ physics ensemble using the MIROC5 coupled atmosphere-ocean GCM without flux corrections: experimental design and results; parametric uncertainty of climate sensitivity Climate Dynamics, Online First ${ }^{\mathrm{TM}}, 23$ July 2012.

8 Yokohata, T., Annan, J.D., Hargreaves, J.C., Jackson, C.S., Tobis, M., Webb, M., Sexton, D., \& Collins, M. (2012) Reliability of multi-model and structurally different single-model ensembles, Climate Dynamics, 39 (3-4), 599-616, doi:10.1007/s00382-011-1203-1.

9 Kolstad, C.D. Fundamental irreversibilities in stock externalities. Journal of Public Economics 60(2): 221-233 (1996).

10 Fisher, A.C. \& Narain, U. Global Warming, Endogenous Risk and Irreversibility. Environmental and Resource Economics 25(4): 395-416 (2003).

11 Heal, G. \& Kristrom, B. Uncertainty and Climate Change. Environmental and Resource Economics 22: 3-39 (2002). 
12 Yohe, G. \& Oppenheimer, M. Evaluation, Characterization, and Communication of Uncertainty by the Intergovernmental Panel on Climate Change - An Introductory Essay. Climatic Change 108: 629-639 (2011).

13 Millner, A., Dietz, S., \& Heal, G. Ambiguity and Climate Policy. NBER Working Paper No. 16050. (2010).

14 IPCC, 2012: Managing the Risks of Extreme Events and Disasters to Advance Climate Change Adaptation. A Special Report of Working Groups I and II of the Intergovernmental Panel on Climate Change [Field, C.B., V. Barros, T.F. Stocker, D. Qin, D.J. Dokken, K.L. Ebi, M.D. Mastrandrea, K.J. Mach, G.-K. Plattner, S.K. Allen, M. Tignor, and P.M. Midgley (eds.)]. Cambridge and New York: Cambridge University Press.

15 Kunreuther, H., Pauly, M. \& McMorrow, S. Insurance and Behavioral Economics: Improving Decisions in the Most Misunderstood Industry, New York: Cambridge University Press. 2013, in press.

16 Roy, A.D. Safety First and the Holding of Assets. Econometrica 20(3): 431-450 (1952).

17 Ellsberg, D. Risk, Ambiguity, and the Savage Axioms. Quarterly Journal of Economics 75: 643-669 (1961).

18 Kunreuther, H., Meszaros, J., Hogarth, R.M., \& Spranca, M. Ambiguity and underwriter decision processes. Journal of Economic Behavior \& Organization 26(3): 337-352 (1995).

19 Cabantous, L., Hilton, D., Kunreuther H., \& Michel-Kerjan, E. Is Imprecise Knowledge Better than Conflicting Expertise? Evidence from Insurers' Decisions in the United States. Journal of Risk and Uncertainty 42: 211-232 (2011).

20 Meinshausen, M., Meinshausen, N., Hare, W., Raper, S. C. B., Frieler, K., Knutti, R., Frame, D.J. \& Allen, M.R. Greenhouse-gas emission targets for limiting global warming to $2{ }^{\circ} \mathrm{C}$. Nature 458: 1158-1162 (2009).

21 Report of the Conference of the Parties on its sixteenth session, held in Cancun from 29 November to 10 December 2010. United Nations Framework Convention on Climate Change, (2011).

22 Allen, M.R \& Frame, D.J., Call off the Quest, Science, 318:582-583 (2007).

23 Gilboa, I. Theories of Decision under Uncertainty. Cambridge: Cambridge University Press (2009). 
24 Klibanoff, P., Marinacci, M., \& Mukerji, S. A Smooth Model of Decision Making under Ambiguity. Econometrica 73(6): 1849-1892 (2005).

25 Savage, L.J. The theory of statistical decision. Journal of the American Statistical Association 46: 55-67 (1951).

26 Wald, A. Note on the consistency of the maximum likelihood estimate. Ann. Math. Statist. 20: 595-601. (1949).

27 Lempert, R. J., Groves, D.G., Popper, S.W. \& Bankes, S.C. A General, Analytic Method for Generating Robust Strategies and Narrative Scenarios. Management Science 52(4): 514-528 (2006).

28 Hall, J.M., Lempert, R., Keller, K., Hackbarth, A., Mijere, C., \& McInerney, D. "Robust Climate Policies under uncertainty: A comparison of Info-Gap and RDM methods." Risk Analysis. DOI: 10.1111/j.1539-6924.2012.01802.x (2012).

\section{Acknowledgements}

Correspondence and Requests for material should be sent to Howard Kunreuther (kunreuther@wharton.upenn.edu). Thanks to Linus Mattauch for research assistance and to Malte Meinshausen for the data used in Figure 1. Simon Dietz, Kristie Ebi, Christian Gollier, Robin Gregory, Benjamin Horton, Elmar Kriegler, Katharine Mach, Michael Mastrandrea, Anthony Millner, Michael Oppenheimer and Christian Träger provided comments on earlier versions of the paper. Partial support for this research came from the Wharton Risk Management and Decision Processes Center's Extreme Events project, the National Science Foundation (SES1062039 and 1048716), the Travelers Foundation, the Center for Climate and Energy Decision Making (NSF Cooperative Agreement SES-0949710 with Carnegie Mellon University), the Center for Research on Environmental Decisions (CRED; NSF Cooperative Agreement SES0345840 to Columbia University) and CREATE at University of Southern California. 
Figure 1: Estimated probability distributions for (bottom axis) Equilibrium Climate Sensitivity from various published studies, collated by ref. 20, and (top axis) corresponding concentrations of $\mathrm{CO}_{2}$ consistent with a long-term $\mathrm{CO}_{2}$-induced warming $T_{\max }$ of $2^{\circ} \mathrm{C}$, given by the expression $C_{2 \mathrm{~K}}=C_{\text {pre-industrial }} \exp \left(-\ln (2) T_{\max } / \mathrm{ECS}\right)$. Current concentrations are $397 \mathrm{ppm}$. 


\section{AUTHORS in ALPHABETICAL ORDER}

\section{Myles Allen}

School of Geography and the Environment

University of Oxford

South Parks Road

OX1 3QY

Email: myles.allen@ouce.ox.ac.uk

Phone: 01865 (2)75895

\section{Ottmar Edenhofer}

Potsdam Institute for Climate Impact Research

P.O. 601203

D-14412 Potsdam

Phone: ++49 (0)331 / 288-2565

and

Mercator Research Institute on Global Commons and Climate Change

Torgauer Str. 12 - 15

D-10829 Berlin

Phone: ++49 (0) 303385537400

Email: Ottmar.Edenhofer@pik-potsdam.de

\section{Christopher B. Field}

Director, Department of Global Ecology

Carnegie Institution for Science

260 Panama Street

Stanford, CA 94305

Email: cfield@ciw.edu

Phone: 6503198024

\section{Geoffrey Heal}

Donald C. Waite III Professor of Social Enterprise

Columbia Business School

New York, NY 10027

Email: Geoff.Heal@gmail.com

Phone: 2128546459

\section{Howard Kunreuther}

James G. Dinan Professor of Decision Sciences \& Public Policy

3730 Walnut St. Room 563 Huntsman Hall

Wharton School, University of Pennsylvania

Philadelphia, PA 19104-6340

E-Mail: Kunreuther@wharton.upenn.edu

Phone: 215 898-4589

\section{Gary W. Yohe}

Huffington Foundation Professor of Economics and Environmental Studies

Wesleyan University

238 Church Street

Middletown, CT 06459 USA

Email: gyohe@.wesleyan.edu

Phone: 860-685-3658 